\title{
¡NO AL MALL BARÓN. SÍ AL MALL DE CASTRO! El Rol de las Subjetividades Sociales chilenas en el proceso de ejercicio efectivo del Patrimonio Cultural como Derecho Universal
}

\author{
Victoria Bustos \\ Universidad Alberto Hurtado, Chile
}

\section{Resumen}

Este artículo investiga dos movimientos ciudadanos. Por una parte, la movilización que se opuso al Mall Barón en Valparaíso, y, por otra, la movilización que estuvo a favor del Mall de Castro en Chiloé. A través de una metodología cualitativa, basada en entrevistas en profundidad y análisis de fuentes, se busca conocer la vinculación de estos movimientos ciudadanos con la activación de la dimensión política del derecho de acceso al patrimonio cultural en la concepción vigente implementada en la política pública. Se reconoce que hay elementos del derecho al patrimonio cultural que no están presentes en ella, en particular la no consideración de la participación ciudadana en la toma de decisiones respecto de su propio patrimonio y tampoco el reconocimiento y la legitimación de nuevos patrimonios correspondientes a las diversas subjetividades sociales existentes al interior de una misma sociedad. Desconocerlos se transforma en un problema de sustentabilidad social que impacta en los niveles de desarrollo humano, bienestar social y en la calidad de nuestra democracia.

Palabras clave: Políticas públicas culturales, patrimonio cultural, participación, realismo social.

NOT TO THE BARON MALL! YES TO CASTRO MALL! The Chilean Social Subjectivities Role in the Process of Effective Exercise of Cultural Heritage as a Universal Right

\begin{abstract}
This paper investigates two citizen movements. On the one hand, the mobilization that opposed to the Mall Baron in Valparaiso, and, on the other hand, the mobilization that was in favour of the Mall of Castro in Chiloé. Through a qualitative methodology, based on in-depth interviews and source analysis, we look for the linkage of these citizen movements with the activation of the political dimension of the right of access to cultural heritage in the current conception implemented in public policy. We recognized that there are elements of the right to cultural heritage that are not present in these experiences. In particular the non-consideration of citizen participation in decision-making regarding its own heritage and the recognition and legitimation of new patrimonies corresponding to the various social subjectivities that exist within the same society. To ignore the above becomes a problem of social sustainability that impacts on the levels of human development, social welfare and the quality of our democracy.
\end{abstract}

Keywords: Cultural public policies, cultural heritage, participation, social realism.

*Dirección de correspondencia [Correspondence address]: Victoria Bustos, Universidad Alberto Hurtado, Chile

E-mail: victoriabustosurbina@gmail.com

\section{Introducción}

Para las organizaciones ciudadanas de Valparaíso pro defensa del patrimonio cultural, instalar un mall o mega centro comercial en el borde costero es una decisión que atenta contra su identidad y 
patrimonio cultural y por ello utilizan la consigna “¡NO al mall Barón!” De otro lado, para la gran mayoría de las organizaciones ciudadanas de Castro, decir "iSÍ al mall de Castro!" es pretender que sus demandas sean escuchadas y respetadas.

Así, vemos a la ciudadanía de Castro, quien en situación de aislamiento de los grandes centros de servicios urbanos, luchar por sus derechos sociales, económicos y culturales, en contra del modo como el Estado y los organismos de cooperación internacional, a través de sus políticas y normativas, traducen las concepciones del derecho internacional vinculadas al patrimonio cultural sin considerar que sus residentes viven su patrimonio, no sólo interactúan de soslayo sino que lo habitan y realizan sus experiencias vitales en él.

En Valparaíso, en tanto, es la ciudadanía la que combate por conservar y proteger su patrimonio de las acciones del Estado y del gobierno local unido a los intereses de la empresa privada, que intentan socavar y desplazar una manera de habitar y construir relaciones sociales diferentes, que le imprimen un modo particular de vida a esta ciudad.

Castro y Valparaíso no son lo mismo y, a la vez, sí lo son. Forman parte de una misma problemática que tiene que ver con la manera que el Estado, a través de la legislación y las políticas públicas en cultura, concibe al patrimonio cultural, abordándolo en términos técnicos, esto es, de identificación, investigación, conservación y protección, asimismo desde la perspectiva de acceso, acercamiento y disfrute, y no en términos políticos como lo es el de abrir un espacio a la participación en la toma de decisiones y consultar a la ciudadanía a la hora de realizar acciones que incidan y afecten su propio patrimonio.

Las características de este conflicto llaman a formular unas cuantas preguntas íntimamente relacionadas: ¿qué lleva a los habitantes de dos ciudades con territorios declarados Patrimonio Cultural de la Humanidad a reaccionar de manera tan opuesta frente a una misma problemática?¿a qué obedecen estas acciones, si se advierte que el Estado ha hecho un esfuerzo consciente a través de las políticas públicas en cultura, específicamente referidas a patrimonio cultural, de trasladar y adoptar los conceptos y categorías que el derecho internacional y los organismos internacionales de cooperación han promulgado y promovido en materia de derechos culturales para hacerlos efectivos? ¿Cuál es el papel que despliegan las subjetividades sociales de esas localidades en el proceso que influye en el cambio de apreciación y abordaje del patrimonio cultural?

Todas estas interrogantes en una gran pregunta, la que se constituye como la pregunta de investigación que guía el presente artículo: ¿por qué la concepción vigente del derecho de acceso al patrimonio cultural implementada en la política pública es insatisfactoria para responder a las demandas del movimiento ciudadano de Castro y de Valparaíso?

Se propone como hipótesis de trabajo que esto se debe a que en la concepción vigente del derecho de acceso al patrimonio cultural implementada en la política pública, no está contemplada la dimensión política del mismo y los movimientos de las ciudadanías de Castro y de Valparaíso la activa.

Teniendo ello en perspectiva, esta investigación busca conocer e interpretar la relación entre la emergencia de estos movimientos ciudadanos de los centros urbanos de Castro y de Valparaíso y la activación de la dimensión política del derecho de acceso al patrimonio cultural en la concepción vigente implementada en la política pública.

\section{El patrimonio cultural desde la Teoría Social Realista}

Las tres dimensiones que integran el patrimonio cultural -noción que se inscribe en el proceso de elaboración de sentido de los sujetos sociales; campo de poder y de acción de la estructura social; derecho universal que cumple un importante rol político que amplía y fortalece las capacidades de incidencia de las personas en la sociedad a favor de la profundización de la democracia y del incremento de los niveles de bienestar y desarrollo humano-se entrelazan con lo que Margaret Archer (2009) denomina el proceso morfogenético de la realidad social. La autora declara que la sociedad es transformable y no tiene una forma inmutable o estado preferido. Esto estaría dado por un doble movimiento en el que se vincula la relación entre agencia y estructura. Por una parte, lo que es en un determinado momento, depende del humano y de sus consecuencias. Por otra, no somos agentes sociales inmutables, porque lo que hacemos y somos como agentes sociales está también afectado por la sociedad en que vivimos y por nuestros propios esfuerzos por transformarla.

De esta forma, la estructura constriñe, limita nuestro accionar, nuestro sentimiento de libertad, sin embargo, ella también nos otorga beneficios para facilitar nuestra existencia. Esa es la ambivalencia de la experiencia cotidiana de las personas comunes y corrientes.

Para Archer, la tarea teórica es vincular dos aspectos cualitativamente distintos de la sociedad: lo social y lo sistémico, o la acción y su ambiente, en lugar de dos características cuantitativamente di- 
ferentes como lo grande o lo pequeño, o macro y lo micro. El dualismo analítico significa enfatizar las vinculaciones, abriendo aquello lo que antes se hacía referencia como el impacto y el efecto de y entre estratos.

Al definir el patrimonio como una noción, queremos dar relevancia a que éste se constituye como el sentir de las diversas subjetividades sociales proyectado tanto en bienes tangibles como intangibles, dando de esta forma sentido de continuidad a las vidas actuales, uniendo su pasado, presente y futuro. Este es el corolario de una reflexión que da cuenta del proceso de revisión y examen de los elementos constitutivos en las principales definiciones que han sido desplegadas en el tiempo y, a su vez, generadas con el aporte de múltiples fuentes provenientes de las ciencias sociales, del derecho internacional, de la Historia y del Arte y de la propia experiencia profesional tenida al interior de instituciones patrimoniales. Noción cuyo contenido ha sufrido transformaciones en el tiempo que hablan de un desplazamiento desde lo exclusivamente material hasta su innegable constitución inmaterial que se inscribe en el proceso de elaboración de sentido de los sujetos sociales, tal como es considerado hoy en día.

Esta exploración indica que son nociones que han oscilado desde la idea comprendida, en un primer momento, como bienes inmuebles, por ello, materiales, privilegiando edificaciones, monumentos históricos, artísticos y objetos conmemorativos como también zonas y barrios, hacia una segunda mirada, donde se instala como una concepción que también reconoce e integra el elemento inmaterial presente en la cultura, lenguas y creencias, modos de vida. "Al modificarse la naturaleza del objeto de protección [...] se afectan las características y los elementos de la constitución del patrimonio cultural, al pasar del límite de los bienes culturales a las manifestaciones culturales en sí mismas, generándose así un nuevo paradigma de lo que debe entenderse por patrimonio cultural" (Tello, 2012).

En el tenor de protección del patrimonio histórico, se concibe, desde el Derecho Internacional, un cambio en la nominación misma del concepto que revela la importancia que estos bienes van adquiriendo para el resto de la sociedad, desmarcándose del núcleo de interés de los especialistas. Con la Carta de Venecia y la Comisión Franceschini, (1964) el término bienes culturales se consolida de manera internacional, aunque ya fuese utilizado con anterioridad en la doctrina jurídica administrativa italiana de 1939 donde se pone en evidencia que es "insuficiente la nominación meramente material de cosas para referirse al patrimonio histórico-artístico y se tiende a utilizar como categoría o noción central la actividad cultural, que comprende no solo determinados bienes sino también utilidades culturales que no son propiamente encuadrables en objetos" (López Bravo, 1999).

\section{Nosotros, la comunidad imaginada y la pluralidad identitaria}

En el origen del patrimonio cultural está la sociedad con sus diversas subjetividades sociales presentes en ella. Subjetividades que configuran sus modos de vida reconocibles por los demás, es decir, con una identidad cultural colectiva cuyos componentes permiten reconocer al patrimonio cultural como derecho humano.

Siguiendo a Larraín (2001), la idea de una identidad colectiva es puramente un artefacto cultural, un tipo de "comunidad imaginada", como expresa Anderson (citado en Larraín, 2001) de la nación. Los miembros de estas comunidades imaginadas son limitados en número, pero "nunca conocerán a la mayoría de sus compañeros miembros, ni estarán con ellos, ni siquiera los oirán, sin embargo en la mente de cada uno de ellos vive la imagen de su comunión. Cada una de estas identidades tiene su propia historia y resonancia individual" (Larraín, 2001).

Ese concepto de comunidad imaginada, ayuda a vislumbrar otros dos aspectos que deben ser considerados a la hora de comprender el dinamismo y la identidad cultural múltiple de un individuo. Para Jorge Larraín, "cada identidad cultural demanda una cantidad diferente de compromiso de cada miembro individual o supone un grado diferente de fraternidad imaginada y que esto puede cambiar históricamente" (2001).Junto al dinamismo, especifica Anderson, también "las identidades culturales pueden coexistir y no son mutuamente excluyentes" (citado en Larraín, 2001).

\section{Los Otros y el auto reconocimiento}

Un segundo elemento importante que integra el proceso social de construcción de identidad es la existencia de "otros" en un doble sentido, tanto como opinión sobre nosotros mismos que internalizamos y, en tanto, diferenciación y auto reconocimiento. La identidad supone la existencia del grupo humano, que de acuerdo a Erikson (citado en Larraín, 2001) "no sólo nos rodea, sino que también está dentro de nosotros (...) es un proceso intersubjetivo de reconocimiento mutuo".

Este auto reconocimiento, según Honneth (citado en Larraín, 2001), toma tres formas positivas: auto- 
confianza, auto respeto y autoestima. "La confianza en sí mismo que deriva del amor o preocupación recibida de los otros. Respeto a su dignidad humana, por lo tanto, respeto a los derechos que acompañan esa dignidad y, estima por su contribución, esto es, el reconocimiento de los otros al aporte de una persona como valioso".

A él se le contrapone un proceso inverso de "falta de respeto" que se transforma en un atentado a la dignidad humana y cuya solución es política. "El abuso o amenaza a la integridad física que afecta la confianza en sí mismo. La exclusión estructural y sistemática de una persona de la posesión de ciertos derechos, lo que daña el respeto de sí mismo. La devaluación cultural de ciertos modos de vida y su consideración como inferiores o deficientes, lo que impide al sujeto atribuir valor social o estima a sus habilidades o aportes"

Tanto el "nosotros" como los "otros" en su doble sentido de diferenciación y auto reconocimiento y éste en su forma positiva y negativa, nos permite comprender la identidad cultural como un proceso dinámico y múltiple que conduce, asimismo, a la idea de expansión y de disputa por el reconocimiento. Para Honneth (citado en Larraín, 2001) "la experiencia de la falta de respeto sería la fuente de las formas colectivas de resistencia y lucha social" Del mismo modo añade, "las personas siempre están luchando por expandir el rango de sus derechos. Por el reconocimiento de esferas mayores de autonomía y de respeto".

Es precisamente el componente activo, de adhesiones y lealtades múltiples, también de disputa por el reconocimiento y el respeto, la idea medular que sostiene que el patrimonio cultural es un derecho humano, y que además, revela su carácter político.

Resulta de la mayor trascendencia la tesis de Larraín para comprender el cambio de enfoque y perspectiva operado en las ciencias sociales respecto de la concepción de cultura y de identidad cultural, que consiguientemente es irradiado a la noción de patrimonio cultural. La identidad, hasta hace poco tiempo, era entendida como modos de vida homogéneos, distinguible y dueña de un patrimonio cultural predicado de la totalidad social. La admisión de la existencia de los grupos subalternos no ofrecía mayores dificultades para el análisis de la misma puesto que se consideraban grupos étnicos y religiosos minoritarios. Esta nueva mirada y perspectiva será refrendada en el Sistema de Naciones Unidas con la Declaración Universal de la UNESCO sobre la Diversidad Cultural de $2001^{1}$.

\footnotetext{
${ }^{1}$ El artículo 1 de la Declaración Universal de la UNESCO sobre la Diversidad Cultural establece que ésta debe ser reconocida y consolidada en beneficio de las generaciones presentes y futuras, y que las creaciones culturales configuran un
}

\section{El derecho a la participación en la vida cultural}

Aunque los derechos culturales fueron expresamente reconocidos bajo el Sistema de Naciones Unidas en la Declaración Universal de los Derechos Humanos de 1948 y ratificados con posterioridad en el Pacto Internacional de Derechos Económicos, Sociales y Culturales de 1966 y en el Protocolo Facultativo del mismo en diciembre 2008; y, otro tanto ha sucedido en los sistemas regionales como el Protocolo Facultativo de San Salvador de 1988 y la Carta Africana de 1976; lo cierto es que, debido a la dificultad de su cumplimiento, se hizo necesario clarificarlos con el objetivo de dilucidar lo que ellos comprenden y protegen.

Es así que en el año 2010, el Centro UNESCO del País Vasco, entrega un documento referido a los Derechos Culturales con el fin de difundir los avances en materia de clarificación que se venían efectuando desde el año 2009 cuando se designó la conformación de dos instancias para precisar los contenidos y alcances.

En el marco del Sistema de Naciones Unidas, la primera acción es la aprobación de un Comité de Derechos Económicos Sociales y Culturales, ${ }^{2}$ para la Observación General número 21, referente al Art. 15.1a del Pacto Internacional de Derechos Económicos, Sociales y Culturales de Naciones Unidas, que habla del "Derecho de toda persona a Participar en la Vida Cultural". Con la meta de "dotar a los gobiernos y administraciones de indicaciones sobre qué contempla ese derecho como elemento que colaboraría a la comprensión e implementación del Pacto en las legislaciones nacionales" (UNESCO ETXEA, 2010).

La segunda, es el nombramiento ese mismo año, de Farida Shaheed como Experta Independiente del Consejo de Derechos Humanos de Naciones Unidas para los Derechos Culturales con el fin de "examinar los medios de superar los obstáculos actuales a la promoción y protección de los derechos culturales" (UNESCO ETXEA, 2010).La experta independiente analizó además, la relación entre los derechos humanos y la diversidad cultural, realzando que los derechos humanos son herramientas para la promoción de la diversidad cultural.

patrimonio que debe ser preservado, realzado y transmitido a las generaciones futuras como testimonio de la experiencia y de las aspiraciones humanas, con el propósito de nutrir la creatividad en toda su diversidad e inspirar un verdadero diálogo entre las culturas (artículo 7). En Luisa Tello (2012: 142).

${ }^{2}$ El 19 de noviembre de 2009 en Ginebra, Suiza. en Derechos culturales. Documentos básicos de las Naciones Unidas. UNESCO ETXEA, 2010. 
Los resultados de esos dos estudios aclaratorios indican que para el Comité de DESC encargados de la Observación General №21, el derecho de participar en la vida cultural se encuentra relacionado con los otros derechos culturales consagrados en el artículo 15, como:

1. El derecho a gozar de los beneficios del progreso científico y de sus aplicaciones (art. 15, párr. 1 b));

2. El derecho de toda persona a beneficiarse de la protección de los intereses morales y materiales que le correspondan por razón de las producciones científicas, literarias o artísticas de que sea autora (art. 15, párr. 1 c));

3. El derecho a la indispensable libertad para la investigación científica y la actividad creadora (art. 15, párr. 3).

Agregan que el derecho de toda persona a participar en la vida cultural está también intrínsecamente vinculado al derecho a la educación (arts. 13 y 14), por medio de la cual los individuos y las comunidades transmiten sus valores, religión, costumbres, lenguas y otras referencias culturales, y que contribuye a propiciar un ambiente de comprensión mutua y respeto de los valores culturales.

La trascendencia de esta observación es que incorpora conceptos que están presentes en otros instrumentos internacionales, como las convenciones de la UNESCO, que ayudan a puntualizar la proyección social y política de este derecho. La participación en la vida cultural comprende, en particular, el derecho de toda persona (sola, en asociación con otras o como una comunidad) a actuar libremente, a escoger su propia identidad, a identificarse o no con una o con varias comunidades o a cambiar de idea, a participar en la vida política de la sociedad, a ejercer sus propias prácticas culturales y a expresarse en la lengua de su elección. Toda persona tiene igualmente derecho a buscar, desarrollar y compartir con otros sus conocimientos y expresiones culturales, así como a actuar con creatividad y tomar parte en actividades creativas.

En esta misma línea, Farida Shaheed, en su informe extrae de los diversos instrumentos reconocidos en los ámbitos universales y regionales los derechos culturales donde distingue y define:

1. Derecho de toda persona a beneficiarse de la protección de los intereses morales y materiales que le correspondan por razón de las producciones científicas, literarias o artísticas de que sea autor/a.
2. Los derechos de las minorías.

3. Derecho de toda persona a participar en la vida cultural de la comunidad

4. Derecho a gozar de los beneficios del progreso científico y sus aplicaciones.

5. El derecho de acceso al patrimonio cultural y su disfrute

Farida Shaheed, justifica su decisión de otorgar un estatuto propio al derecho de acceso al patrimonio, estableciendo que este derecho forma parte de las normas internacionales de derechos humanos y tiene su base jurídica en los señalamientos que hace el Comité de Derechos Económicos, Sociales y Culturales en la Observación General No. 17, relativa al derecho a participar en la vida cultural, en su relación indisoluble con este último y, por la importancia que en los ámbitos internacional y nacionales se ha dado a la protección del patrimonio cultural, se advierte la necesidad de que el acceso al mismo constituya un derecho cultural independiente (UNESCO ETXEA, 2010), ya que éste se configura tanto por bienes monumentales o artísticos específicos como por un sistema de valores, creencias, ideologías, tradiciones, etcétera, que permite a las personas crear su propia cultura y desarrollar sus productos culturales.

Respecto al contenido normativo del derecho, en el informe mencionado se advierte la definición de acceso y disfrute, estableciéndose como conceptos interdependientes que transmiten la capacidad de conocer, comprender, entrar, visitar, hacer uso, mantener, intercambiar y desarrollar el patrimonio cultural, y beneficiarse del mismo, además de la creación de otros, sin impedimentos políticos, religiosos, económicos o físicos. Se subraya en dicho texto, que no se trata solamente de un uso o beneficio sino de la participación en su determinación, interpretación y desarrollo, así como en el diseño y aplicación de políticas y programas de preservación y salvaguardia (párr.58)

El acceso al patrimonio cultural implicaría, de manera específica: los aspectos físicos, económicos, a la información y, a los procedimientos de adopción de decisiones sobre el mismo. Y se establece entre otras distinciones, que la participación en la toma de decisiones comprende las relativas a su supervisión, procedimientos y recursos administrativos y judiciales.

Se fijan en este informe también, las obligaciones generales de derechos humanos (respetar, proteger y cumplir) relativas al ejercicio del derecho de acceso y disfrute del patrimonio cultural. 
En cuanto a las limitaciones a dicho acceso, se encuentran todas aquellas prácticas contrarias a los derechos humanos y a la dignidad de las personas, puesto que, el patrimonio cultural junto con contribuir a la protección de la diversidad cultural también puede ser reconocido de manera selectiva para obligar a las personas y comunidades a asimilarse a la sociedad mayoritaria, por cuanto, "la destrucción del patrimonio de un grupo determinado puede ser parte de la intención de suprimir al propio grupo, y por ello, constituir un delito de lesa humanidad" 3 (Tello, 2012: 191)

En dicho informe se determina que "pensar el acceso al patrimonio cultural y su disfrute como un derecho humano es un criterio necesario y complementario de la preservación y salvaguardia del patrimonio cultural" (Tello, 2012: 189). "Asimismo, que preservar y salvaguardar un objeto o una manifestación en sí misma obliga a entender los derechos de las personas y las comunidades en relación con ese objeto o manifestación, y conectar el patrimonio cultural con su fuente de producción, ya que éste se halla vinculado tanto a la dignidad como a la identidad humanas" (Tello, 2012: 189).

\section{Metodología}

Esta es una investigación cualitativa, cuya perspectiva holística e inductiva permite "experimentar la realidad tal como otros la experimentan" (Taylor y Bogdan, 2000). Además, lo que define al enfoque cualitativo "es el conjunto de prácticas interpretativas que hacen al mundo visible, lo transforman y convierten en una serie de representaciones en forma de observaciones, anotaciones, grabaciones y documentos" (Hernández et al., 2006).

Asimismo, la presente investigación responde a un diseño de Caso único con la modalidad Situacional, que según la clasificación presentada por Bogdan y Biken, es el "estudio de un acontecimiento desde la perspectiva de los que han participado en el mismo"(Gutiérrez y Delgado, 1995).

Respecto de las técnicas de investigación cualitativas utilizadas, el enfoque presentado se basa principalmente en dos: entrevistas en profundidad para el caso de Chiloé y el análisis de fuentes de informaciones primarias y secundarias en particular para

\footnotetext{
${ }^{3}$ En las resoluciones del Tribunal Penal Internacional para la ex Yugoslavia se hizo énfasis en que la destrucción intencional de construcciones religiosas en particular equivalía a una forma de genocidio cultural, además del significado histórico y cultural de los inmuebles. Así se demuestra que las infracciones a las normas que protegen el patrimonio cultural pueden constituir violaciones sumamente graves a los derechos humanos.
}

Valparaíso.

Considerando que las entrevistas son testimonios que se convertirán posteriormente en información relevante para responder a las preguntas de investigación, las que a su vez, contribuirán a comprender un fenómeno y a generar conocimiento. Son datos que dan a entender los motivos subyacentes [latentes], los significados y las razones internas del comportamiento humano(Hernández et al., 2006: 583).

En Chiloé, las entrevistas fueron conducidas en los ambientes naturales de los participantes como son los barrios, oficinas, residencias y plaza central de la ciudad de Castro ${ }^{4}$. Los actores consultados fueron:

1. Doris Chiguay Chacón; presidenta de la Unión Comunal de Juntas de Vecinos de Castro.

2. Vesna Yurac Romero, presidenta del Colegio de Arquitectos delegación Chiloé.

3. Edward Rojas, arquitecto y dirigente de la organización social Ciudadanos por Castro.

4. Dante Montiel Vera, Secretario Municipal y Ministro de Fe de la Acción Pública de la consulta ciudadana del 15 de abril de 2012 efectuada por la I. Municipalidad de Castro.

5. Soledad Guarda Andrade, Encargada del Departamento de Cultura de la I. Municipalidad de Castro, quien dio su opinión a título personal.

6. Renato Cárdenas Álvarez, investigador, miembro de la Academia Chilena de la Lengua y etnólogo chilote. Ejerció el rol de informante clave. Se define al informante clave como aquella persona del lugar donde realizamos el trabajo de campo, fundamental para el proceso de la investigación, con quien establecemos de una forma respetuosa una relación sistemática de aprendizaje. En este sentido, entonces, la empatía es fundamental así como la aceptación por parte de la persona que se constituye en nuestro informante ${ }^{5}$. Fue quien gestionó y facilitó el encuentro con los entrevistados antes mencionados. Cabe señalar que entre el informante clave y la investigadora existe un fuerte lazo de amistad derivado del trabajo profesional en pro de la difusión de la cultura tradicional chilota, lo que permitió haber residido

\footnotetext{
${ }^{4}$ En ese entorno se realizaron cinco entrevistas en profundidad entre el 20 y el 24 de mayo de 2014.

${ }^{5}$ Restrepo, Eduardo: Técnicas etnográficas, (s/f) en www.ram-wam.net Borrador de un texto escrito para la Especialización en Métodos y Técnicas de Investigación en Ciencias Sociales, de la Fundación Universitaria Claretiana Colombia (FUCLA).
} 
en su casa durante el periodo de trabajo en terreno y contribuyó a que el tema estuviese en permanente conversación favoreciendo ampliamente la investigación.

7. Lorenzo Berg Costa, arquitecto y miembro del equipo que elaboró el expediente técnico para la postulación de las iglesias de Chiloé a la declaratoria de patrimonio cultural de la humanidad por la UNESCO. La entrevista se realizó en Santiago, el jueves 5 de junio de 2014 .

Las preguntas que dieron y orientaron la entrevista fueron ¿Cuál es su opinión respecto del Patrimonio de Castro en relación al mall?, ¿Cómo se ve afectado?.

En Valparaíso, en tanto, se empleó fundamentalmente la técnica de análisis de fuentes secundarias para analizar la problemática allí expuesta con la utilización de la plataforma Internet mediante la revisión de prensa ciudadana digital y de medios de comunicación convencionales on line, así como los weblogs de las organizaciones ciudadanas donde las acciones, opiniones e impresiones sobre el movimiento ciudadano fueron vertidas, para posteriormente ser analizadas en su contenido intertextualmente, cuyos resultados fundamentan el corpus de esta investigación. Cabe señalar que las fuentes primarias también estuvieron presentes con la entrevista en profundidad a Arturo Michell (Ciudadano Michell $)^{6}$, con quien se continuó conectada mediante la "amistad" a través de la red social Facebook y el "seguimiento de sus posteos" que permitió la recolección y análisis de las fuentes de información de carácter secundaria.

Recurrir a Internet, particularmente, a las redes sociales como recurso para la obtención de datos, se debe a las múltiples posibilidades que brinda como plataforma de comunicación efectiva que junto a la entrega de información de diversa índole faculta a través del acceso a sitios web de redes sociales y de comunidades virtuales donde es posible la interacción entre los usuarios y acceder a información personal y también grupal, contribuyendo a profundizar el análisis de contenido por su capacidad para albergar un texto que leído e interpretado adecuadamente nos abre las puertas al conocimiento de diversos aspectos y fenómenos de la vida social. Es lo que sucede con el sitio web Facebook, la red social más popular en Chile donde la investigadora y el integrante de la organización social Ciudadanos por Valparaíso y economista Arturo Michell Ciudadano Michell-, somos usuarios registrados en $\mathrm{su}$ plataforma y formamos parte de nuestros mu-

\footnotetext{
${ }^{6}$ Realizada el 8 de marzo de 2013 en la zona del Muelle Prat del Puerto de Valparaíso.
}

tuos contactos o "amigos" 7 .

Por el mismo periodo se efectuó el seguimiento a los weblog, como exponentes de la opinión de las organizaciones ciudadanas.

- Plataforma Urbana, www.plataformaurbana.cl sitio destinado al debate e información de programas, políticas públicas y proyectos urbanos que afecten a los habitantes de la ciudad.

- No al mall Barón, www.noalmallbaron.cl sitio destinado a informar sobre las distintas etapas del conflicto y de las decisiones de sus actores.

- Análisis Informativo, www.anin.cl es un sitio de informaciones y análisis de la realidad noticiosa chilena con énfasis en reportajes y temas de investigación.

- Borde Costero www.bordecostero.cl sitio de denuncia sobre decisiones que afectan a la ciudadanía de Valparaíso.

- Cerro Concepción.org, www.cerroconcepcion.org, sitio administrado por el abogado Pablo Andueza y Camilo Vargas, que han promocionado una fuerte campaña en contra de la construcción del mall. Pablo Andueza junto a Pablo Aravena escribieron Valparaíso Reclamado: demandas ciudadanas de la ciudad-puerto. El libro resume la presentación realizada por diversas organizaciones ciudadanas ante la comisión evaluadora de la UNESCO en noviembre de 2013.

- Ciudadanos por Valparaíso http:/ / ciudadanosporvalparaiso.blogspot.com/ es el sitio de la agrupación del mismo nombre que se opone a la edificación del mall desde 2007.

Un weblog es un sitio web periódicamente actualizado que recopila cronológicamente textos y/o artículos de uno o varios autores donde el más reciente aparece primero, con un uso o temática en particular, siempre conservando el autor la libertad de dejar publicado lo que crea pertinente. Son sitios web basados en enlaces, noticias y opiniones, escritos con un estilo informal y subjetivo. Los weblog que poseen cierta cultura bloguer tienden a enlazarse unos a otros en una sección que se denomina Blogroll. La capacidad de trazar los enlaces que dan y reciben unos blogs con unas características determinadas permite visualizar las redes en las que estos blogs participan.

\footnotetext{
${ }^{7}$ De esta forma fue posible el seguimiento diario a los posteos entre marzo de 2013 y julio de 2014
} 
También hubo análisis de documentos y artículos digitales a través de la revisión de textos elaborados en los sitios web de prensa digital ciudadana. Asimismo, el seguimiento a la prensa convencional a través de sus sitios web. Los medios de comunicación analizados fueron los siguientes: El Ciudadano, La Otra Voz, El Martutino, El Mercurio de Valparaíso; Radio Universidad Católica de Valparaíso; Radio Placeres; El Mercurio; Emol.com; La Tercera; El Dínamo; Revista Planeo.UC; El Desconcierto; CIPER Chile; Soy Chile; El Repuertero; Radio Universidad de Chile ${ }^{8}$.

De este modo, las principales dimensiones cualitativas de análisis se expresaron como manifestaciones de tres elementos dialécticamente relacionados: Posición y profundización frente al debate; Acción y movimiento ciudadano; y valoración de lo patrimonial y su implicancia en el desarrollo.

Se utilizó una muestra no probabilística intencionada, ya que lo que interesa para los objetivos es la potencialidad del caso, la riqueza de la información que los sujetos nos puedan proporcionar, de una forma coherente que posibilite la credibilidad del sujeto que está siendo investigado.

Se eligieron a las organizaciones de la sociedad civil más representativas de los movimientos ciudadanos de Castro y de Valparaíso. Se incluye al grupo experto, es decir, a los profesionales e investigadores que se relacionan con el patrimonio cultural desde un aspecto de conocimiento y manejo conceptual. Asimismo, a la autoridad edilicia como representante del gobierno local.

En Valparaíso, desde la sociedad civil, lideran el movimiento las organizaciones sociales: Ciudadanos por Valparaíso, Borde Costero, No al Mall Barón, Cerro Concepción, Fundación Valparaíso. Reúnen a profesionales, académicos, estudiantes, trabajadores portuarios, artistas, etc., todos ellos férreos opositores a la construcción del mall de Puerto Barón.

Para el caso de Castro, dirigen el movimiento las organizaciones sociales: Unión Comunal de Juntas de Vecinos de Castro instancia que a través de su presidenta apoya la construcción del mall Paseo Chiloé. Se exceptúan las juntas vecinales Facundo Pérez y Nueva Aurora que interpusieron una demanda de nulidad de derecho público contra la I. Municipalidad y el Grupo PASMAR S.A. ante el Juzgado de Letras de la ciudad. Ciudadanos por Castro es la organización liderada por arquitectos, profesionales de la cultura y expertos que se oponen férreamente a la construcción del mega centro comercial.

\footnotetext{
${ }^{8} \mathrm{El}$ período de revisión fue entre marzo de 2001 y julio de 2014 .
}

Por último, el movimiento también fue guiado por el Colegio de Arquitectos delegación Chiloé, entidad gremial que a través de su presidenta Vesna Yurac denunció sobre la irregularidad en la modificación del plano regulador de la ciudad que el Concejo Municipal aprobó en 2008, en el medio electrónico de investigación periodística CIPER Chile.

Con respecto a la metodología empleada y la validez del uso de ambas propuestas para la recogida de datos, se descansa en la estrategia del análisis de contenido textual con la característica intensiva; "en ella se trata de integrar en el análisis todos los elementos presentes en el texto, reconstruyendo sus relaciones sistemáticas en el mismo". La estrategia también es intertextual "ya que busca determinar el sentido virtual [latente] de un texto por medio de sus relaciones con otros textos" y discriminativa, "ya que convierte cada texto o cierto grupo de ellos en dominios analíticos diferentes, con vistas a realizar comparaciones entre los mismos" (Gutiérrez y Delgado, 1995).

Se reconoce que

"el análisis de contenido se basa en la lectura (textual o visual) como instrumento de recogida de información, lectura que a diferencia de la lectura común debe realizarse siguiendo el método científico, es decir, debe ser, sistemática, objetiva, replicable, y valida. En ese sentido es semejante en su problemática y metodología, salvo algunas características especificas, al de cualquier otra técnica de recolección de datos de investigación social, observación, experimento, encuestas, entrevistas, etc. No obstante, lo característico del análisis de contenido y que le distingue de otras técnicas de investigación sociológica, es que se trata de una técnica que combina intrínsecamente, y de ahí su complejidad, la observación y producción de los datos, y la interpretación o análisis de los datos"

\section{Resultados}

\section{¡NO al mall Barón!}

\section{La ciudad imaginada}

Uno de los puntos centrales de este debate tiene que ver con las decisiones de la autoridad sobre la proyección de Valparaíso en el marco de la globalización: ciudad patrimonial, con la declaratoria de la UNESCO; ciudad puerto con su actividad productiva histórica; capital cultural, con la instala- 
ción de la sede nacional del Consejo de la Cultura, son los slogans o frases del marketing que hablan de los intentos de la autoridad para "vender" Valparaíso. Cada uno de estos "slogans" designa un relato, una narración que hace referencia a la totalidad de la ciudad y a la totalidad de sus habitantes. Giandomenico Amendola (2000: 292), sociólogo y urbanista, problematizó gran parte del fin de siglo la transformación del modelo de las ciudades y la instauración de una nueva ciudadanía, desarrollada en base al relato: una narrativa de la ciudad independiente del contenido complejo de sus habitantes (Bailey, 2014).

Se da inicio a este proceso de "creación" hacia fines de la década de los noventas con la reconversión de uso del suelo de un tramo del borde costero del puerto de Valparaíso, que si bien, en el origen fue una demanda ciudadana por acceder a él ${ }^{9}$, hoy en día está instalada en el imaginario colectivo como la decisión con mayor rechazo por los grupos ciudadanos debido a la futura construcción del mall y de un proyecto inmobiliario.

El cambio de uso de suelo, es un proyecto que forma parte del Plan Maestro vigente de la Empresa Portuaria de Valparaíso (EPV) ${ }^{10}$, iniciativa que se diseñó y se comenzó a ejecutar desde principios de la década pasada y cuya finalidad perseguía tanto el desarrollo de la actividad portuaria como el posicionamiento de la ciudad en el plano nacional e internacional. De esta manera, la nueva gestión portuaria estableció definir zonas en el borde costero de acuerdo a su destino productivo. Los dos sectores extremos, el sector Yolanda-Barón por el norte, y el que va desde el Molo de Abrigo hasta

\footnotetext{
${ }^{9}$ En el Cabildo Abierto realizado en Valparaíso en 1991, se expresó la aspiración por acceder al borde costero, aunque fuera en forma parcial. Desde ahí surge el debate por definir a Valparaíso como Ciudad-Puerto. A comienzos del 2000, nace la idea de desarrollar Puerto Barón, entonces EPV comienza a estudiar e implementar el Proyecto, tras el mandato político que dio el Gobierno a su Directorio. Luego de esto, en el año 2006 se adjudica el desarrollo del proyecto a la empresa Plaza Valparaíso S.A.

El Proyecto se enmarca en los lineamientos del Plano Seccional Borde Costero Sector Barón, y dispone de: Estudio de Impacto sobre el Transporte Urbano (2011); Estudio de Tsunami y Medidas Preventivas, inédito y voluntario del concesionario; Anteproyecto aprobado por la Ilustre Municipalidad de Valparaíso (2012), y Proyecto de construcción, con estricto apego y respeto a la normativa. Fuente: EPV, 2014 http://www.puertovalparaiso.cl/

${ }^{10}$ La Empresa Portuaria de Chile (EMPORCHI) administradora estatal desde los años sesenta del siglo pasado de la actividad portuaria del país, ve afectada su gestión con la promulgación de la Ley de Puertos de 1981, fragmentando y reduciendo la titularidad a diez de ellos, quedando Valparaíso bajo su administración y otros 27 puertos nacionales en manos de la empresa privada. Esta titularidad estatal termina con la creación de empresas autónomas que la modernización portuaria obliga. Naciendo en 1998, la Empresa Portuaria de Valparaíso (EPV) uno de los actores principales de este conflicto social.
}

la Caleta El Membrillo, por el sur, se destinaron a reserva portuaria, es decir, quedaron reservados para la ampliación de la infraestructura propia del puerto.

Si bien a EPV le corresponde la responsabilidad de la reconversión del uso de suelo del borde costero, en este proyecto no estaba sola puesto que el Plan Maestro era parte de una estrategia de gran envergadura del Gobierno Central destinada a impactar e instalar a Valparaíso en el marco de la globalización, como una ciudad que pudiese competir por las inversiones de las grandes empresas internacionales e insertarse en la corriente principal del turismo internacional. Con ese objetivo surge el Plan Valparaíso $^{11}$, propuesto por el gobierno del presidente Ricardo Lagos para ser ejecutado entre los años 2001 y 2010 como proyecto Bicentenario.

\begin{abstract}
"Vivimos, en la era de la globalización, mi deber como Presidente es trabajar para que Chile entre al mundo global, aprovechando al máximo sus oportunidades que se nos ofrecen, disminuir los riesgos y cuidar que los beneficios de esa globalización, esos beneficios se distribuyan equitativamente entre todas las familias"
\end{abstract}

(Ricardo Lagos, mensaje presidencial 21 de mayo 2002)

Junto con abrir la ciudad al mundo e instalarla como un portal de ingreso de capitales y personas, también estaba su consideración para postularla como Sitio de Patrimonio Mundial por la UNESCO, lo que finalmente ocurrió en julio de $2003^{12}$. .Esto es posible de apreciar en el Plan Valparaíso y en

${ }^{11}$ Dentro de los ejes del Plan Valparaíso, el principal estaba conformado por el borde costero, por cuanto en él se localiza y concentra la mayor parte de la población regional, el doble centro mayor Valparaíso/Viña del Mar y el centro mediano San Antonio. Este eje concentra además importantes actividades económicas - como la actividad marítima portuaria y de servicios relacionados con el comercio, el turismo y la pesca artesanal.

${ }^{12}$ En 1997 el Consejo de Monumentos Nacionales, siendo su vicepresidenta la Sra. Marta Cruz-Coke, que a la vez era la Directora de la DIBAM, junto con el suscrito (Ángel Cabezas) que ocupaba el cargo de secretario ejecutivo del Consejo de Monumentos Nacionales, (1994-2006) iniciaron los contactos oficiales con la Municipalidad de Valparaíso y su Concejo Municipal para lograr el respaldo local para la nominación de un sector de la ciudad como Sitio del Patrimonio Mundial ante UNESCO. Al comienzo hubo ciertas reticencias, voces que planteaban que tal nominación sería un problema más que una ventaja para Valparaíso, pero finalmente se logró el respaldo de sus autoridades lo cual fue recibido con beneplácito por los porteños de manera creciente. Se reconocía así también el trabajo de muchos arquitectos e historiadores porteños que por muchos años registraron su patrimonio, lo difundieron y acariciaron dicha idea como la arquitecta Sra. Myriam Wiesberg. Comenzó entonces un largo y difícil proceso (Cabezas, 2009). 
el documento de candidatura donde se hacen referencias como iniciativas mutuamente relacionadas, especialmente aquel que alude a la reconversión del borde costero ${ }^{13}$.

El fundamento que sostiene el proceso de postulación contiene aspectos de orden de trazado urbano, de arquitectura, también geográfico y geomorfológico. "Las condiciones geográficas fueron en este caso tan fuertes, que la adaptación de las formas construidas al medio dio lugar a un resultado plenamente original y singular" (Waisberg, 1998).

En esta candidatura no solo se apela como argumento de justificación a los elementos constitutivos y característicos del sector de postulación, el Casco histórico y el sector del Muelle Prat, sino que a su vez, se amplía y se extiende en el contexto global de la ciudad. Este punto es muy importante de resaltar para la comprensión del conflicto en estudio, por cuanto, éste formará uno de los elementos clave de su constitución.

\begin{abstract}
"Los valores patrimoniales de la ciudad están contenidos en ella como un todo, y no en un sector específico. En efecto, la diversidad de las soluciones arquitectónicas y urbanísticas, y el carácter multifacético de la ciudad, han determinado una delimitación del sitio que comprende varios sectores, cada uno de los cuales tiene un carácter particular. Las formas de relación entre estas diferentes áreas, y en particular las formas de relación entre el plan y el cerro, son también valiosas en sí mismas. Por otra parte, la ciudad de Valparaíso no tiene un centro histórico, en el sentido tradicional del término, sino que se desarrolló generando diversos núcleos, en un proceso dinámico"
\end{abstract}

(Consejo de Monumentos Nacionales, 2001: 4).

Sin embargo, y no obstante los avances de la Estrategia de Desarrollo Regional, los resultados logrados no son suficientes para lograr el impulso requerido, lo que lleva a crear una nueva instancia de crecimiento implementando el Programa de Recuperación y Desarrollo Urbano de Valparaíso (PRDUV) desplegado entre los años 2006 y 2012, también conocido como Valparaíso Mío e impulsado por la Subsecretaría de Desarrollo Regional y Administrativo (SUBDERE) con un financiamiento por parte del Estado con un crédito del Banco Interamericano de Desarrollo (BID). El objetivo de este programa era contribuir a la revitalización de la

\footnotetext{
${ }^{13}$ En el capítulo 4 destinado a la descripción de las medidas de protección y administración del bien postulado se señala: f.1 instrumentos de planificación regional y comunal estrategia de desarrollo regional y f.3) plan de transformación urbana del borde costero. Informe de postulación de Valparaíso como Sitio al Patrimonio Mundial.
}

ciudad de Valparaíso poniendo en valor el patrimonio urbano como fundamento de nuevas actividades económicas y sociales. El programa fue proyectado para una duración de cinco años.

Paralelamente, se ve la necesidad de generar un programa que orientase sus esfuerzos hacia la conservación y protección del sitio declarado Patrimonio Mundial por UNESCO., surgiendo el Plan Director de Gestión Patrimonial (PDGP), iniciativa a cargo de la I. Municipalidad de Valparaíso y del PRDUV, "para que permita una óptima gestión, administración y operación del Sitio, cuyo objetivo fundamental sea contar con un conjunto articulado de objetivos, estrategias, actividades, proyectos y programas que, a través de una mirada integral de la ciudad, oriente la conservación del área de valor universal y siente las bases para la gestión de su desarrollo y sustentabilidad futura".

\section{El malestar ciudadano}

Al observar con detenimiento las expresiones vertidas por los ciudadanos, vemos que la consigna representa la agudización del malestar de los habitantes por las decisiones de la autoridad respecto de los bienes públicos que afectan su cotidianidad, su historia y su identidad; junto con tener la clara percepción de no ser escuchados lo suficiente. Arturo Michell, de la organización "Ciudadanos por Valparaíso", en una entrevista en la prensa destacó que "en ningún proyecto han escuchado la petición de los vecinos. Esperamos que se detenga la construcción del mall. La principal queja es que nunca se nos ha tomado en cuenta. Anuncian conversaciones pero nunca se ha consultado a nadie, los ciudadanos no somos dueños de nuestro destino. Basta que alguien de Santiago quiera hacer algún proyecto y eso pareciera ser la ley".

Esta percepción de no ser escuchados como corresponde y de insuficiente respeto hacia su opinión, se contrasta con los dichos de la autoridad que, como en el caso de la Estrategia de Desarrollo Regional 2001-2010, expresamente señala "su formulación fue producto de un ejercicio amplio y participativo, coordinado por la Secretaría Regional Ministerial de Planificación y Coordinación. Se realizaron doce seminarios que fueron organizados por las universidades regionales, seis temáticos y seis territoriales, uno en cada capital provincial continental. Otros dos seminarios fueron organizados por el SERNAM y la SEREMI de Gobierno" ${ }^{14}$.

\section{Las movilizaciones dejan en claro que no es una}

\footnotetext{
${ }^{14}$ Raúl Allard, ex intendente Valparaíso. En documento Estrategia de Desarrollo Regional 2001-2010. Publicado por SUBDERE (2001).
} 
oposición por oponerse a una medida del bando contrario o al gobierno de turno. Es la oposición derivada de la no inclusión de su opinión, de su parecer. Las maneras de conducir la participación ciudadana que se han llevado hasta hoy por los distintos gobiernos post dictadura, no son suficientes ni en la cantidad ni en la calidad de las mismas. Precisamente es uno de los grandes reclamos.

\section{La inexigibilidad de los derechos culturales}

La insuficiente acogida a la opinión de la ciudadanía ha llevado a las organizaciones de la sociedad civil a recurrir a instancias de la UNESCO como una manera de proteger la zona del borde costero que se ve amenazada por la construcción del mall, arguyendo la pérdida o disminución del valor universal excepcional del sitio de patrimonio mundial y que tanto el Comité del Patrimonio Mundial como ICOMOS son los encargados de supervisar.

Esto es posible de apreciar en el blog de Ciudadanos por Valparaíso (Durbelis, 2006), que en una columna destinada a divulgar las normas para defender su ciudad se esgrimen leyes y artículos, tanto de la Constitución Política de la República como de derecho administrativo, la Ley General de Urbanismo y construcciones, etc., sin embargo, no se hace mención alguna de los derechos culturales, que están reconocidos y vigentes desde 1989.

Asimismo, destaca la gestión del dirigente de la organización Ciudadanos por Valparaíso Arturo Michell de concurrir a Unesco con la finalidad de ser escuchado y que este organismo ejerza presiones al Estado chileno para conservar el Valor Universal Excepcional de Valparaíso.

"El economista Arturo Michell, conocido en las redes sociales como el "Ciudadano Michell", desde hace un par de semanas se encuentra en Paris, Francia, donde viajó encomendado por una decena de sindicatos y federaciones de Valparaíso con el fin de denunciar ante la UNESCO y la comunidad internacional, una serie de situaciones que ponen en riesgo la calidad patrimonial de la Ciudad Puerto" 15

Estas presiones junto a otras dieron como resultado la realización por parte de un experto independiente enviado por el Comité de Patrimonio Mundial de UNESCO y contratado por el Estado chileno a través de la Dirección de Bibliotecas Archivos y Museos (DIBAM), de un Estudio de Impacto Patrimonial sobre los proyectos Terminal 2 del Puerto de

\footnotetext{
${ }^{15}$ http://www.anin.cl/nota/67/3698/misi \%C3 \%B3nsecreta-del-ciudadano-michell-paris-contra-del-mallbar \%C3\%B3n
}

Valparaíso y Puerto Barón ${ }^{16}$. Donde concluye que el área histórica de Valparaíso declarada Patrimonio de la Humanidad por la Unesco 2003, sufriría un impacto alto, permanente e irreversible, ocasionado por el Terminal 2 del Puerto, y un impacto leve producto de Puerto Barón ${ }^{17}$.

En ese mismo texto se alude a la Política Nacional de Desarrollo Urbano como una herramienta clave para la integración del patrimonio cultural a la planificación de la ciudad, particularmente, el correspondiente a las comunas.

\begin{abstract}
"Este EIP reitera que Chile está implementando una nueva Política Nacional de Desarrollo Urbano, gobernada por el Consejo de Monumentos Nacionales, y uno de sus objetivos clave es la integración de identidad y patrimonio dentro de los planes territoriales a través de una herramienta única de regulación de planificación urbana, conocida como Plan Regulador Comunal"
\end{abstract}

(EIP, 2016:13)

El debate y la confrontación hablan del derecho al patrimonio cultural, sin embargo, no hay conciencia de la exigibilidad sobre él y de acudir a un tribunal sobre la base del espacio que la misma constitución política chilena menciona en su artículo $5^{\circ}$ inciso $2^{\circ}$ :

"El ejercicio de la soberanía reconoce como limitación el respeto a los derechos esenciales que emanan de la naturaleza humana. Es deber de los órganos del Estado respetar y promover tales derechos, garantizados por esta Constitución, así como por los tratados internacionales ratificados por Chile y que se encuentren vigentes" ${ }^{18}$.

Como lo expresa Humberto Nogueira (2009), "tal perspectiva promocional de los derechos fundamentales está expresamente contenida en la Constitución chilena en el artículo $5^{\circ}$, por asegurar los derechos fundamentales en base no sólo a la explicitación formal de los derechos asegurados por las fuentes formales del derecho internacional. Lo trascendente es que el ordenamiento jurídico asegure

\footnotetext{
${ }^{16}$ Solicitud realizada en la última reunión efectuada entre el 28 de junio y el 8 de julio de 2015 en Bonn (Alemania)

${ }^{17}$ Estudio dado a conocer el 25 de mayo de 2016 por la Intendencia de Valparaíso. http://www.plataformaurbana.cl/archive/2016/06/02/estudioidentifica-cuales-son-los-impactos-patrimoniales-del-t2-ypuerto-baron-en-valparaiso/

${ }^{18}$ Inciso modificado por el artículo único, $\mathrm{N}^{\circ} 1$ de la ley de Reforma Constitucional $\mathrm{N}^{\circ}$ 18.825. Ver, además, Pacto Internacional de Derechos Civiles y Políticos de 1966 (Decreto $\mathrm{N}^{\circ} 778$, D.O. 29 de abril de 1989; Pacto Internacional de Derechos Económicos, Sociales y Culturales de 1966 (Decreto N 326, D.O. 27 de mayo de 1989; Convención Americana sobre Derechos Humanos (Pacto de San José de Costa Rica, Decreto $\mathrm{N}^{\circ} 873$, D.O. 5 de enero de 1991).
} 
los derechos sociales y sus instituciones garantizadoras administrativas y jurisdiccionales, como normas jurídicas vinculantes y de efecto directo al menos en su contenido esencial, además del contenido mínimo de tales derechos asegurados por el derecho internacional".

El desconocimiento y proyección de esa normativa provoca no hacer uso efectivo del derecho como tal y, mueve a acudir a otras instancias que no necesariamente están para l protección de personas y colectivos, sino para exigir al Estado parte el cumplimiento de lo acordado.

\section{¡SÍ al mall de Castro!}

Más que una consigna, es la afirmación rotunda de la ciudadanía de Castro a la pregunta formulada en la consulta pública realizada por el Municipio de la comuna en abril de $2012^{19}$. acerca de la edificación de un mega centro comercial emplazado en las cercanías de la Iglesia San Francisco de Castro, declarada en el año 2000 bien patrimonio mundial por la $\mathrm{UNESCO}^{20}$.

El conflicto que estalla dos años después de iniciadas las obras, enfrenta al gobierno local, la empresa privada y divide a la ciudadanía castreña a la que pone en acción resignificando a las juntas vecinales y creando organizaciones sociales pro defensa del patrimonio de Castro.

\footnotetext{
${ }^{19}$ Las preguntas fueron:1.- ¿Está de acuerdo con la construcción del mall en Castro en las condiciones que se está llevando a cabo (ubicación, arquitectura, tamaño)? 2.- ¿Está de acuerdo con la construcción de estacionamientos subterráneos en el centro de Castro, incluyendo la plaza? 3.-¿Es urgente el By-pass para Castro?

De un universo de 19000 personas que conformaban el Registro electoral de la ciudad, 5.059 electores votaron en la consulta pública no vinculante. De ellos el 94,04\% lo hizo a favor de la pregunta 1. Es importante señalar que el alcalde en ejercicio, Nelson Águila Serpia, fue elegido en 2008 con 8.296 votos en las elecciones municipales de 2008 y fue reelegido en las de octubre de 2012 con 7.834 preferencias que equivalía al $55,78 \%$ de los votos. Se esperaba la asistencia de 7000 votantes.

${ }^{20}$ El Comité del Patrimonio Mundial inscribió a las iglesias de Chiloé en la Lista del Patrimonio Mundial en el 2000, debido en particular, a que el bien constituye un ejemplo único en América Latina de la remarcable fusión de las tradiciones culturales europeas e indígenas para producir una forma única de arquitectura de madera. La cultura mestiza resultante de las actividades de los jesuitas misioneros en los siglos XVII y XVIII se ha mantenido intacta en el archipiélago de Chiloé, y alcanza su máxima expresión en las excepcionales iglesias de madera. Estas representan una tradición iniciada por la Misión Jesuita Peripatética en los siglos XVII y XVIII, seguida y enriquecida por los franciscanos en el siglo XIX y todavía vigente en la actualidad. Las iglesias simbolizan además la riqueza intangible del Archipiélago de Chiloé y la plena integración de su arquitectura en el paisaje y medio ambiente, así como los valores espirituales de las comunidades.
}

Las organizaciones sociales que agrupa la Unión Comunal de Juntas de Vecinos de Castro $^{21}$ son férreos defensores de la construcción del mall y colisiona con la visión de arquitectos e investigadores, principalmente, que se oponen al diseño y emplazamiento del edificio considerado como un atentado al patrimonio cultural de la ciudad, perspectiva que representa el Colegio de Arquitectos delegación Chiloé y la organización social Ciudadanos por Castro.

La I. Municipalidad de Castro a través de la Dirección de Obras Municipales es la entidad que autorizó la construcción del mall Paseo Chiloé y es el centro de las acusaciones y críticas por parte de quienes se oponen a la acción.

\section{El estallido}

La disputa surge a partir de una imagen. Unas fotografías de un edificio en construcción que comienzan a circular por las redes sociales (Facebook y Twitter) las que en febrero de 2012 son publicadas en el sitio web Plataforma Urbana ${ }^{22}$, especializado en la difusión de temas sobre la ciudad desde diversas perspectivas.

La divulgación de estas imágenes despierta una ola de críticas y de opiniones contrarias a su edificación que exceden los límites locales, y se extienden al plano nacional, incitando el interés de otros medios de comunicación por conocer la situación. De este modo, VesnaYurac, presidenta del Colegio de Arquitectos delegación Chiloé, concede una entrevista al medio electrónico de investigación periodística CIPER Chile donde critica el actuar del Alcalde y del Concejo Municipal en la aprobación de esa obra, denunciando la irregularidad en la modificación del plano regulador de la ciudad que el Concejo Municipal decretó en 2008 "solo para que se aprobara el proyecto (del mall) que se estaba presentando a la Dirección de Obras de la Municipalidad" 23 Comentarios y denuncias que por su implicancia y envergadura, provocan un gran impacto

\footnotetext{
${ }^{21}$ Se exceptúan las juntas vecinales Facundo Pérez y Nueva Aurora que interpusieron una demanda de nulidad de derecho público contra la I. Municipalidad y el Grupo PASMAR S.A. ante el Juzgado de Letras de la ciudad. Las polémicas imágenes del mall de Castro en Plataforma Urbana, publicada el 29 de febrero de 2012. http://www.plataformaurbana.cl/archive/2012/02/29/laspolemicas-imagenes-del-mall-de-castro/

${ }^{22}$ Las polémicas imágenes del mall de Castro en Plataforma Urbana, publicada el 29 de febrero de 2012. http://www.plataformaurbana.cl/archive/2012/02/29/laspolemicas-imagenes-del-mall-de-castro/

${ }^{23}$ El Concejo Municipal de Castro modificó el plan regulador solo para aprobar la construcción del mall. Entrevista a VesnaYurac publicada en CIPER Chile, el 2 de marzo de 2012. www.ciperchile.cl
} 
en la sociedad castreña y enciende el estallido y su posterior división.

"como Colegio de Arquitectos de la delegación de Chiloé nos opusimos a la modificación del plano regulador. Hicimos una presentación a la Intendencia de la época (hablamos con el consejero regional Marcelo Fuentes quien se lo comunicó al intendente de entonces, Sergio Galilea) para que no lo aprobara ni patrocinara. Sin embargo, el Concejo Municipal realizó gestiones de manera express. Por ello, no sólo el alcalde está involucrado en la aprobación del proyecto, sino el Concejo Municipal que en su mayoría estuvo de acuerdo en modificar el plano"

(El Concejo Municipal de Castro modificó el plan regulador solo para aprobar la construcción del mall. Entrevista a Vesna Yurac)

Naturalmente, esto suscitó la respuesta inmediata del Alcalde Nelson Águila y de los integrantes del Concejo Municipal quienes por el mismo medio refutaron las acusaciones ${ }^{24}$ :

"El plano regulador de Castro fue aprobado el año 2007 y su primera modificación se materializó el 06 de noviembre de 2008, oportunidad en la que ésta fue publicada. Así no es efectivo que el plano regulador comunal se haya modificado para favorecer directamente a la empresa PASMAR S.A., pues su permiso de construcción fue otorgado siete meses antes que entrara en vigencia la modificación en cuestión. Sin perjuicio de ello, las modificaciones efectuadas al plano regulador en el año 2008 no se refieren a las normas específicas de la zona C1, solo se incorporó en la zona el uso Terminal de buses. Nada se modificó en las calles Ramírez y Serrano donde se emplaza el referido proyecto. Por lo demás sin la referida modificación el proyecto se podía ejecutar legalmente"

(Plataforma Urbana)

Al respecto, Felix Castro, vocero de la organización opositora a la construcción del mall, Ciudadanos por Castro, reconoce que

\footnotetext{
${ }^{24}$ Carta de desmentido de la Municipalidad de Castro publicada en CIPER Chile, 5 de marzo de 2012. www.ciperchile.cl
}

"...hay que decirlo claramente, las modificaciones al plan regulador que permitieron esta construcción, fueron abiertas y expuestas por la autoridad municipal (...) hoy podemos estar de acuerdo o no con el Plan Regulador, pero no se puede desconocer que fue sobre la base de éste -y no vulnerándolo- que se gestó el proyecto del mall. E insisto: este plan no se aprobó de espaldas a la gente. Este plan, que no protege adecuadamente el casco histórico de la ciudad, que no pone condiciones de materialidad, fue conocido en su momento. Y los habitantes de Castro no reaccionamos"

(Félix Oyarzún: La lección para los ciudadanos tras el mall de Castro. Artículo publicado en CIPERChile el 9 de marzo de 2012.)

La arquitecta Yurac también señala en dicha publicación que ellos como entidad gremial se opusieron, en su oportunidad, a los cambios y modificaciones del plan regulador que serían llevadas a efecto, declarando que "no fuimos escuchados y nuestra propuesta simplemente no se consideró" 25 .

La respuesta edilicia dice que aquella crítica no se ajusta a la verdad, por cuanto, en una carta enviada por el Colegio de Arquitectos delegación Chiloé, en marzo de 2008 al respecto señala:

\begin{abstract}
"Dichos cambios tienen la finalidad de permitir que una mayor cantidad de privados invierta en la comuna, lo que nos parece relevante y de suma importancia para el desarrollo comunal y provincial. Nos parece que las modificaciones que se nos proponen son necesarias y completamente adecuadas para el desarrollo de la comuna, pero también creemos necesario un estudio más profundo que asegure la factibilidad de crecimiento y desarrollo que la comuna demanda"
\end{abstract}

(Félix Oyarzún: La lección para los ciudadanos tras el mall de Castro. Artículo publicado en CIPERChile el 9 de marzo de 2012.)

Estas acusaciones y reclamos mutuos se sostuvieron permanentemente. En ellas hubo descalificaciones graves, que no solo aparecen en la prensa o en los weblogs, sino que se percibe en el énfasis de las palabras y de las ideas que se transmiten en las conversaciones en donde el tema del mall fue consultado, y que no dejan de llamar la atención por cuanto, sus habitantes indistintamente al grupo social que pertenezcan, proclaman que sus relaciones sociales horizontales, sus relaciones vecinales y familiares solidarias, son el soporte, "la viga maestra de la sociedad chilota" 26 .

\footnotetext{
${ }^{25}$ CIPER Chile publicación citada.

${ }^{26}$ Entrevista Dante Montiel. Castro, 23 mayo 2014.
} 
Sin embargo, estas relaciones comunitarias se están viendo afectadas por la construcción del mall y los propios chilotes dan cuenta de este fenómeno en dos direcciones. Para Soledad Guarda, el conflicto los está conmoviendo en su cotidianidad, infiltrándose en las zonas más sólidas de la comunidad castreña.

\begin{abstract}
“... está afectando en nuestra convivencia, porque yo creo que igual se está volviendo como intolerable entre el sector del sí al mall y del no al mall. Hay unas tremendas pugnas de repente de las juntas de vecinos. Están todos como enojándose unos con otros. Cosa que no sucedía con otro tema".
\end{abstract}

(Soledad Guarda)

En tanto, Renato Cárdenas, realiza una reflexión con una mirada hacia el futuro donde compara el efecto que la llegada de las salmoneras en los ochentas provocaron al interior de la sociedad en su manera de relacionarse

\begin{abstract}
“... cuando hay un cambio de esa envergadura que afecta lo económico que afecta a la parte más fuerte del funcionamiento de un grupo puede ser desastroso.(...) lo que pasó con las salmoneras es posible que se acentúe con este tipo de vínculos que ya son distintos. Se pierde la relación vecinal. Y eso es lo que pasó antes y esperemos que lo que pase ahora no sea tan violento"
\end{abstract}

(Renato Cárdenas)

El tono beligerante y de desprestigio indica que este conflicto esconde algo más que la molestia por la construcción de un edificio, de un mall. Son opiniones radicalizadas que denotan una tensión en la sociedad que la controversia en este tipo de materias dejó en evidencia.

\section{Las claves del conflicto}

Un primer paso lógico de acercamiento a este debate ciudadano es hacerlo desde una entrada legal, referida a la vulneración de la normativa vigente sobre construcción que proviene tanto del plan regulador comunal como de la Ordenanza General de Urbanismo y Construcciones del Ministerio de Vivienda y Urbanismo, no obstante al poco andar, se comprende que esta perspectiva reduce la complejidad del tema que no alcanza a explicar la profundidad de la división. Si bien es cierto, tiene asidero real por cuanto gatilló la controversia y el enfrentamiento, sin embargo, allí no radica el centro del problema como tampoco lo es la construcción del mall per se ni el consumismo unido a él.

En rigor, la exaltación al consumo es llevado diariamente a cada casa por la televisión a través de la publicidad comercial, la que se instaló en el archipiélago en la década de los setenta cuando la señal de Televisión Nacional llega a todo Chile y también con el establecimiento de las salmoneras en los ochentas, por lo tanto, el Paseo Chiloé es un punto más de esta línea que se orienta a ese lugar. Lo que sí realiza esa construcción y la movilización ciudadana en torno de ella, es mostrar los otros aspectos que estaban latentes al interior de la comunidad. Es así entonces, que la pregunta sobre el impacto que la construcción del mall provoca en su ciudad contribuye a que aquellos afloren y se hagan perceptibles para examinar.

El primer indicador en esta dirección se da con la consulta ciudadana, que señala que la sociedad castreña está dividida, no en un cincuenta y cincuenta, sino que en, prácticamente un $80 \%$ y un $20 \%$, se tome desde la perspectiva que se elija. Porque para los opositores, quienes votaron a favor representan un quinto de la población, y para aquellos que votaron favorablemente, su decisión corresponde a la mirada de la mayoría de los habitantes de Castro, “...unos grupos a favor y un mínimo minimorum que está en contra (...) la gente chilota, digamos que ha estado toda su vida acá, están todos a favor del mall" 27 .

Se une a lo anterior, las impresiones que los comentarios y palabras de los entrevistados dejan relucir y que la revisión de artículos en la prensa y blogs acompañan, los que en conjunto permiten identificar la existencia de tres elementos que estarían subyacentes en este conflicto: el tema de la identidad cultural, sus distintas versiones y el patrimonio, es uno de ellos. Se encuentra en estas opiniones también, la necesidad de un diálogo público abierto sobre lo que se quiere de ciudad. Y, tercero, que es por sobre todo el más significativo que esas conversaciones muestran, tiene que ver con la molestia a las disposiciones del gobierno central y de entidades externas al archipiélago, y las pocas posibilidades de tomar sus propias decisiones y de ser escuchados:

${ }^{27}$ Ibíd. 
"Te voy a hablar desde mí....Lo que pasa es que Chiloé toda su vida fue una provincia expoliada. Históricamente una provincia absolutamente expoliada... y esa visión que surgió con el tema del mall, yo creo que la comunidad lo siente como una oportunidad, entre comillas, del progreso para su vida cotidiana, para su desarrollo. Chiloé ha sido una provincia marginada por todos los gobiernos...[para los habitantes] en su mayoría, de alguna manera te diría que hay ese rechazo interno que se provoca un poco con las políticas públicas que nunca han considerado a Chiloé...."

(Dante Montiel)

\section{Identidad chilota}

La identidad chilota con sus versiones y entremezclada con las concepciones de patrimonio va fluyendo en cada uno de los entrevistados y van formando un contrapunto que da cuenta cómo sienten su ciudad y su territorio. Y allí, entre los diálogos, se van percibiendo las diferencias; sin embargo, para todos sin excepción, su identidad descansa, principalmente, en la manera de construir sus relaciones sociales horizontales y solidarias y en la manera de habitar el territorio producto de su insularidad.

Se podría sintetizar y hablar de una concepción tradicional que se concentra en la cultura de la madera extraída de sus bosques y de su relación con la naturaleza, de su especialización en las técnicas del uso de este material para construcción de viviendas e iglesias como también de artefactos de utilización cotidiana y festiva. De su conexión con la divinidad expresada en su religiosidad de la que las iglesias son testigos y a la vez protagonistas.

Para Renato Cárdenas,

"La historia local se construye a fuerza de memoria; de recuerdos personales y de una herencia comunitaria donde cada individuo es una suerte de vehículo, de receptáculo que atraviesa las aduanas de la muerte, para llevar a la otra generación el avance que los ancestros lograron o heredaron como eficaces instrumentos para seguir viviendo"

(Renato Cárdenas)

$\mathrm{Y}$ es precisamente ese sentido identitario tradicional el que se ve afectado con la construcción del mall y lo que más hiere a sus detractores. Para Lorenzo Berg Costa, "...la ciudad como el mayor objeto patrimonial heredado y que debiera garantizar el bien común de la vida social, ha sido resultado de una trasgresión de parte de ciertos agentes privados..."

(Lorenzo Berg Costa)

Esta mirada tradicional forma un contrapunto con una concepción distinta cuyo sentido identitario se dirige hacia la integración y asimilación de la sociedad chilota a la corriente principal del país y que el mall de alguna manera hace de puente, sin destruir su ciudad, incluso intensificaría sus relaciones sociales al transformarse en un futuro cercano en "la plaza pública"28.

En la misma dirección, aunque de manera más absoluta se expresa Doris Chiguay. Para ella, la construcción del mall no solo trae beneficios de orden social sino que su sentido identitario de alguna forma se reforzaría y no se vería alterado.

\begin{abstract}
"Los chilotes necesitamos modernización. Mire, ¿acaso porque yo soy indígena voy a andar todavía dando alaridos por la plaza y con una pluma en la cabeza? No. Déjenme a mí también modernizarme, ¿no cree usted? ¡Qué venga el mall! ¡Que dé puestos de trabajo, que cree puestos de trabajo! Que tengamos un espacio de esparcimiento, y espacios públicos de uso comunitario"
\end{abstract}

(Doris Chiguay. Presidenta Unión Junta de Vecinos de Castro, 22 de mayo 2014.)

La idea de continuidad, de unión, de ser parte con el sistema imperante en el resto de territorio nacional se confirma con el comentario efectuado por Dante Montiel para quien “...la dignidad e inclusión viene dada por el mall y no por el patrimonio. Es un factor democrático, partícipe del desarrollo que viene".

\section{Diálogo ciudadano}

Otro de los elementos que en este conflicto subyace es la necesidad de un debate público abierto sobre lo que se quiere de ciudad. En esa dirección apunta la opinión de Félix Oyarzún, vocero de Ciudadanos por Castro,

\footnotetext{
${ }^{28}$ Dante Montiel, Secretario Municipal
} 
"la ciudadanía debe participar activamente en la próxima modificación del Plan Regulador a fin de no tener uno débil que desproteja el casco histórico. Es demasiado fácil no participar y luego dedicarse a culpar a las autoridades. Somos un territorio frágil y debemos protegerlo"

(Oyarzún, 2012).

Sin embargo, hasta la actualidad no se ha dado un diálogo ciudadano donde se converse sobre lo que se quiere y hacia dónde dirigirse.

\section{Molestia ciudadana}

Existe un tema que es coincidente en prácticamente todos los entrevistados en cuanto al malestar que provoca en la ciudadanía las decisiones del gobierno central o local o también de cualquier entidad venida de afuera, que sin consultarles su parecer, son sentidas como impuestas y no pensadas para los habitantes del archipiélago y que el emplazamiento y diseño del mall contribuye a mostrar como ejemplo de los tantos proyectos y disposiciones que se han efectuado con anterioridad. La opinión de Renato Cárdenas es muy clara al respecto.

"...en términos del mall hay que siempre situarlo en un contexto de la historia, del pasado. O sea el mall es un elemento más que se suma a una serie de proyectos y formas de desarrollo que se han ido aplicando en Chiloé y que no van a la par con la dinámica del lugar. Con su cultura, con su forma de vida, sino que se han impuesto. Lo que yo le llamo los proyectos en Chiloé pero no para Chiloé (...) entonces es la prepotencia y el mal gusto con que se instala la empresa en Chiloé"

(Renato Cárdenas)

Apreciación que Doris Chiguay también comparte y lo siente como una agresión al derecho de elegir, de decidir lo que quieren tener y vivir como ciudadanos de Castro y de Chiloé.

\begin{abstract}
"¿Y por qué nosotros los castreños no?... los de afuera tienen que venir a mandarnos y a opinar y a ponernos la nota...Estos señores que todos viven protestando, que viven alegando que el edificio que está feo, que esto y que lo otro, que no atoniza(sic), son todos de afuera. Preocúpense de Rengo, de Santiago, del Costanera Center y qué se yo, y dejen a los chilotes vivir la vida nuestra. Los chilotes necesitamos modernización".
\end{abstract}

(Doris Chiguay)
$\mathrm{Y}$ es un rechazo que también se proyecta en las decisiones que se han tomado respecto de su propio patrimonio cultural de la ciudad que habitan y quieren donde la opinión de Dante Montiel representa ese sentir

\begin{abstract}
"Pero el tema del patrimonio, a mí, tal como tú... me preocupa porque llega un momento en que, he escuchado comentarios de gente acá que, no es que no le interese, pero lo ven como algo tan marginal, problema de afuera (...) esto (la postulación de las iglesias de Chiloé) fue el arquitecto Barrientos, fue uno de los que dirigió esta especie de carrera para hacer eso. Yo creo que importante pero, no sé si fue tan sentido por las comunidades"
\end{abstract}

(Dante Montiel)

Se observa de esta manera, un sentimiento compartido de falta de consulta por parte de la autoridad central o local para los cambios que se entregarán a la ciudad, que afectan tanto el patrimonio arquitectónico como a las relaciones sociales y a sus habitantes en su calidad de destinatarios de esas transformaciones. En este sentido, la construcción del mall representa un indicador más de esas decisiones que disminuyen su calidad de vida y su entorno. Renato Cárdenas se expresa de la siguiente manera:

\begin{abstract}
"Deteriorado, claro. O sea, es que lo que pasa en este caso es el concepto de lo urbano. Es la totalidad de las construcciones que hacen ciudad y que donde resaltan, como te decía, fundamentalmente estos dos puntos que son la iglesia y el mall. Si lo vemos en un plano general eso va a aparecer como un destacado. Entonces, el tema es que eso afea. Pero no es solamente eso. Hay otras formas de construcciones en distintos lugares, las mismas poblaciones. Las poblaciones son muy feas, porque el Ministerio de Vivienda no tiene un concepto de construir patrimonialmente. No hay una búsqueda, no es cierto, de retomar lo patrimonial y aplicarlo en las casas, en las viviendas sociales".
\end{abstract}

(Renato Cárdenas)

En ese contexto, la consulta pública tuvo gran importancia, por primera vez la ciudadanía es consultada acerca de un tema que los involucra a todos. Ha sido un ejercicio de resolver una situación sin mandato, sin intermediarios, decidir por ellos mismos. Aunque para quienes se oponían y se oponen a esta construcción, la pregunta pública fue un montaje y un engaño a los electores, idea y sentimiento que Renato Cárdenas sintetiza muy bien en sus palabras 
"El Municipio comenzó una campaña para desautorizar a las voces disidentes y llama un plebiscito (...) con una publicidad increíble (...). Convoca juntas vecinales con cierto tinte político donde ellos podían manejar eso. Y llaman a votar. Votó el $23 \%$ de la población que estaba inscrita en los padrones electorales. Nosotros, los que éramos disidentes no quisimos prestarnos a ese juego, porque era una triquiñuela muy burda. Además el edificio ya estaba instalado. Entonces la pregunta fundamental que engañó a la gente era que si querían o no querían un mall".

(Renato Cárdenas)

Distinta es el parecer de Dante Montiel, para quien la ciudadanía que acudió a votar fue mucho más de la esperada

"Un dato interesante, fíjate que votaron cerca, sino me equivoco unas siete mil a ocho mil personas, que para la ciudad de Castro es una cantidad enorme. Votaron muchas más (personas) que para las campañas políticas o incluso en el mismo Santiago cuando hacían estas pre campañas electorales. Entonces es una cantidad importante. Y de alguna manera, no es que se haya ratificado lo que se quiera construir allí, pero, la comunidad se expresó con esa consulta de opinión".

(Dante Montiel)

\section{Responsabilidad compartida}

En rigor, la consulta pública no arrojó vencedores y vencidos, mostró la distancia y diferencia entre concepciones de identidad y modos de concebir la ciudad y su patrimonio. Además dejó en evidencia que todos ellos en conjunto son la ciudadanía de Castro, por lo tanto, en las decisiones sobre su ciudad, archipiélago y entorno tienen una responsabilidad compartida, no basta con acusarse, con apuntar con el dedo y restarse de la obligación y responsabilidad que poseen.

La falta de atención y aplicación de parte de la institucionalidad, como la carencia de responsabilidad y de sentido de afecto por el otro, se manifiesta abiertamente en la problemática presentada. Esto también es posible de extender al grupo experto, donde no hay una autocrítica, no hay un reconocimiento a la falta de responsabilidad, como gremio, ante el error cometido de no haber fiscalizado a tiempo, no tras dos años de ocurrido el emplazamiento, o de no haber estado lo suficientemente alertas para impedir o detener el anteproyecto que afectaba a toda la ciudad y en cambio se opta por traspasar a la ciudadanía y a la alcaldía el costo del compromiso social y ciudadano, restándose asimismo como voz autorizada y como voz ciudadana. También en ellos recae, como entidad colegiada, no haber propiciado las instancias de incentivar un diálogo, un consenso e infiltrar en la ciudadanía que el diseño de esa construcción no era ni es la apropiada ni para la ciudad ni para su patrimonio y que existen otras y muchas más para lograr el objetivo.

Sin embargo, se recurrió al camino de la descalificación y la denuncia. Se construyó un discurso referido a la ciudadanía como aquel otro que no sabe apreciar su ciudad y su patrimonio,

"Ésa es la visión de la modernidad: no tiene nada que ver con defender o no el patrimonio de Castro. Eso es puramente aspiracional, en un país en que lo aspiracional lo comanda absolutamente todo"

(Sebastián Gray, presidente del Colegio de Arquitectos de Chile. Entrevista en Revista Capital www.capital.cl)

Asimismo se le imputó al Municipio las irregularidades en que efectivamente incurre y no obstante ello, no son ilegales, y a la vez minimiza la consulta ciudadana como un recurso sin validez, de legitimación a una acción indebida.

Como también se minimiza o desconoce la responsabilidad que le cabe a la propia institucionalidad estatal mandatada para conservar el patrimonio:

\footnotetext{
"Hay algo que te quería comentar que aquí se mezcla otra cosa. Cuando se declararon las iglesias patrimonio de la humanidad, en ese tiempo se le ordenaron al Consejo de Monumentos Nacionales, eso la gente no lo sabe, que ellos tenían que elaborar un cono de protección de la iglesia, y el cono de protección todavía no lo hacen en ninguna parte de Chiloé, ni de Castro menos"
}

(Dante Montiel)

Es, precisamente, estos vacíos institucionales lo que este conflicto despierta y deja en evidencia obligando a tomar las medidas necesarias.

Al respecto, Cabeza señaló que a través del Consejo de Monumentos Nacionales se están haciendo importantes esfuerzos para proteger los entornos de las 16 construcciones, "nos falta seguir protegiendo el entorno de las iglesias, hemos protegido cerca de un $50 \%$ de las declaradas patrimonio, pero debemos seguir avanzando para evitar que sigan sucediendo 
situaciones como las del mall de Castro", dice Cabeza sobre los desafíos que siguen pendientes en torno a ellas" 29 .

En cuanto al conflicto mismo, uno de los reparos que Faride Shaheed realiza en su informe, dice relación a que la protección del patrimonio cultural no desvincule a los miembros de la comunidad del mismo patrimonio. Conservadurismo fundamentalista, es el extremo del lado permisivo o relativista de aceptar lo que sea. Hay un límite y es la dignidad de las personas. Se cruza el límite de la protección y el resguardo hacia el espacio de la detención en el tiempo, de encapsular bajo un valor y homologar a todos. Eso tampoco es patrimonio.

\section{Conclusiones}

A la luz de Margaret Archer (2009), es posible comprender que la emergencia de este conflicto se inscribe en el efecto relacional o de juego mutuo permanente entre estructura y agencia, entre los actores institucionales y las organizaciones ciudadanas y de la tensión existente derivada del elemento histórico presente en el imaginario de éstas últimas, referida a la falta de representatividad en las decisiones e intervenciones de la autoridad y la molestia que ello provoca, como elemento clave que viene a potenciar la gravedad del debate.

Siguiendo esta línea, es posible indicar que las acciones, peticiones y reclamos de las organizaciones ciudadanas pro defensa del patrimonio cultural de Castro y de Valparaíso lo evidenciaron en dos direcciones: en primer lugar, muestran el desconocimiento respecto de los derechos culturales, en específico del derecho de acceso al patrimonio cultural en tanto recurso de protección de demandas de esta naturaleza que, paradojalmente y como consecuencia no esperada, contribuyen a activar la dimensión política del mismo, al evidenciar que las dimensiones implementadas en la política pública en vigencia no son idóneas para satisfacer sus requerimientos.

Es precisamente este desconocimiento del derecho cultural, en específico del derecho de acceso al patrimonio cultural, el que conduce a las organi-

\footnotetext{
${ }^{29}$ Unesco aprobó informes presentados por Chile sobre el estado de conservación de Sitios de Patrimonio Mundial: http://www.monumentos.cl/consejo/606/w3article-52158.html04-jul-2015 Como respuesta a lo acontecido en la $37^{\mathrm{a}}$ reunión (Phnom Penh, junio de 2013), donde el Comité del Patrimonio Mundial solicitó una misión conjunta de monitoreo reactivo UNESCO/ICOMOS a las iglesias de Chiloé. Dicha misión, conducida por un experto de ICOMOS Internacional y un representante de la Unidad de América Latina y el Caribe del Centro del Patrimonio Mundial de la UNESCO, se llevó a cabo en diciembre de 2013.
}

zaciones ciudadanas a acudir a instancias distintas como la UNESCO, con el objetivo de encontrar solución a sus demandas. Aunque, el organismo de cooperación internacional no es tribunal ni corte de justicia, por lo tanto no posee las competencias jurídicas para dirimir en un caso de incumplimiento de un derecho cultural. Su incidencia tiene el límite de lo técnico, sujeto al sitio declarado y a la zona de amortiguamiento, debe velar por su protección y conservación y hacer exigible al Estado parte el compromiso adquirido.

Sin embargo, las organizaciones ciudadanas al recurrir a esa entidad a través del ICOMOS Chile, y utilizarla como recurso de protección de un derecho, provoca este doble impacto y visibiliza que la implementación de un derecho cultural por una política pública, particularmente del que nos preocupa, debe ser en su totalidad, que deben estar expresamente descritas todas las dimensiones que lo componen como se demuestra en los casos revisados. Puesto que, no basta con asegurar su conservación, identificación e investigación como tampoco apropiarse de él a través del conocimiento, del saber qué y cómo es y a quién o a quienes perteneció o pertenece, es necesario e imperioso hacer explícita la dimensión política que él contiene, de manera que, participar en la determinación, en la toma de decisiones que afectan a su propio patrimonio cultural sea un derecho especificado en ella.

Un segundo aspecto, es que la activación de la dimensión política del derecho de acceso al patrimonio cultural, condujo a la reorganización de los actores locales que tomaron un posicionamiento frente a la intervención de acuerdo a sus propias visiones identitarias, creándose nuevas organizaciones sociales con un carácter específicamente pro defensa del patrimonio como Ciudadanos por Castro, Comité de Defensa de Valparaíso, Ciudadanos por Valparaíso, entre otras. Además, se rearticularon y potenciaron otras bajo el mismo sentido, como lo fue la Unión Comunal de Juntas de Vecinos de Castro y el Colegio de Arquitectos delegación Chiloé.

Por otra parte, estos conflictos muestran la carencia de una mirada holística que integre en la planificación de la ciudad las voces de sus habitantes junto al respeto por su patrimonio. Existen políticas asignadas a revertir la situación observada tanto en Valparaíso y Castro como en distintos lugares del país, a través del Plan Regulador Comunal inmerso en la Política Nacional de Desarrollo Urbano, sin embargo, se siguen planteando situaciones como las descritas porque, en el nivel comunal, que es en donde ocurren las mayores vulneraciones, tampoco existe una política que promueva la formación de asociaciones patrimonialistas que logren configurar una Unión Comunal Patrimonialista que defienda 
los intereses de los ciudadanos de manera permanente en los espacios designados para ello, como lo es el Consejo Comunal de Organizaciones Sociales, el tercer pilar del gobierno comunal. Si bien es cierto allí sólo es posible la voz, no lo es menos, que unidos a las fuerzas políticas que el Concejo Municipal posee, puedenn lograr contener y generar modificaciones importantes en pro de la defensa del patrimonio de los grupos que habitan la comuna.

Esta situación habla de la necesidad de fomentar e impulsar entre la ciudadanía la difusión de los derechos culturales, particularmente del derecho de acceso al patrimonio cultural.

Asimismo, hoy en día, ya no es posible que la ciudadanía permanezca pasiva ante las decisiones de la autoridad, menos en lo que a sus derechos culturales refiere. Esto se puede apreciar claramente en los casos expuestos, donde se acostumbraba a que las decisiones y las controversias viniesen desde el grupo experto en contra o a favor de las medidas que el gobierno central, regional o local adoptase o tuviese por adoptar, sin consulta de ambas partes, a los directamente afectados, sus voces representaban a esa ciudadanía en silencio.

En estos momentos se requiere del respaldo ciudadano, se requiere de la consulta pública y de su aprobación y validación. La ciudadanía también se siente y debe ser responsable de las acciones y de los problemas de la sociedad, se siente y debe ser parte activa de esta sociedad, no solo receptora pasiva de decisiones tomados por otros, donde solo queda el espacio para ser acatadas. El patrimonio cultural debe dejar de ser visto como una preocupación de "los entendidos", sino ser considerado como lo que verdaderamente es: un derecho humano que nos concierne a todos. Es el reconocimiento a la diversidad humana, que es el derecho a la vida en su más amplia expresión de sentido y significado, que es el derecho a la inclusión de lo diferente que enriquece a la humanidad y que su límite es la dignidad humana.

\section{Referencias}

Amendola, G. (2000). La ciudad postmoderna. Ed. Celeste.

Archer, M. S. (2009). Teoría social realista: En enfoque morfogenético. Ediciones Universidad Alberto Hurtado.

Bailey, G. (2014). Valparaíso, ciudadanía patrimonial: un mandato de orden artificial.

Consejo de Monumentos Nacionales (2001). Postulación de las iglesias de chiloé como sitio de patrimonio mundial/ unesco. Cuadernos del Consejo de Monumentos Nacionales, (23).

Gutiérrez, J. y Delgado, J. M. (1995). Métodos y técnicas cualitativas de investigación en ciencias sociales. Síntesis.

Hernández, R., Fernández, C., y Baptista, P. (2006). Metodología de la investigación.

Larraín, J. (2001). Identidad chilena. LOM ediciones.

López Bravo, C. (1999). El patrimonio cultural en el sistema de derechos fundamentales. Número 76. Universidad de Sevilla.

SUBDERE (2001). Estrategia de Desarrollo Regional 2001-2010. Subsecretar'1a de Desarrollo Regional y Administrativo, Gobierno de Chile.

Taylor, S. y Bogdan, R. (2000). Introducción a los métodos cualitativos.

Tello, L. (2012). El derecho al patrimonio común de la humanidad: origen del derecho de acceso al patrimonio cultural y su disfrute. Comisión Nacional de los Derechos Humanos.

UNESCO ETXEA (2010). Derechos culturales. Documentos básicos de Naciones Unidas. Centro Unesco del País Vasco. 